\title{
Pro- and anti-apoptotic CD95 signaling in T cells
}

\author{
Maren Paulsen ${ }^{*}$ and Ottmar Janssen
}

\begin{abstract}
The TNF receptor superfamily member CD95 (Fas, APO-1, TNFRSF6) is known as the prototypic death receptor in and outside the immune system. In fact, many mechanisms involved in apoptotic signaling cascades were solved by addressing consequences and pathways initiated by CD95 ligation in activated T cells or other "CD95-sensitive" cell populations. As an example, the binding of the inducible CD95 ligand (CD95L) to CD95 on activated T lymphocytes results in apoptotic cell death. This activation-induced cell death was implicated in the control of immune cell homeostasis and immune response termination. Over the past years, however, it became evident that CD95 acts as a dual function receptor that also exerts anti-apoptotic effects depending on the cellular context. Early observations of a potential non-apoptotic role of CD95 in the growth control of resting T cells were recently reconsidered and revealed quite unexpected findings regarding the costimulatory capacity of CD95 for primary $T$ cell activation. It turned out that CD95 engagement modulates TCR/CD3-driven signal initiation in a dosedependent manner. High doses of immobilized CD95 agonists or cellular CD95L almost completely silence T cells by blocking early TCR-induced signaling events. In contrast, under otherwise unchanged conditions, lower amounts of the same agonists dramatically augment TCR/CD3-driven activation and proliferation. In the present overview, we summarize these recent findings with a focus on the costimulatory capacity of CD95 in primary T cells and discuss potential implications for the T cell compartment and the interplay between T cells and CD95L-expressing cells including antigen-presenting cells.
\end{abstract}

\section{Introduction}

Members of the 'tumour necrosis factor receptor' (TNFR) superfamily and their ligands are crucial regulators of cellular activation and death. According to their structural composition and/or cellular function, the TNFR family can be further divided into the three subgroups of 'death domain' (DD)-containing receptors, 'TNFR-associated factor' (TRAF) binding receptors and decoy receptors. The eponymous 'TNF receptor-1' (TNFR-1, TNFRSF1), CD95 (Fas, APO-1, TNFRSF6) and 'TNF-related apoptosis inducing ligand' (TRAIL) receptors (DR4/TNFRSF10A, DR5/TNFRSF10B), contain cytoplasmic death domains, which are essential for the direct induction of cell death. In contrast, the TNFR family members TNFR-2, CD27, 4-1BB (CD137), OX-40 (CD134), 'herpesvirus entry mediator' (HVEM), CD30 and 'glucocorticoid-induced TNFR family related protein' (GITR) belong to the subgroup of TRAF binding receptors that lack a characteristic DD, but harbor 4-6

\footnotetext{
* Correspondence: m.paulsen@ikmb.uni-kiel.de

Christian-Albrechts-University of Kiel Institute of Immunology, University Hospital Schleswig-Holstein Campus Kiel, Arnold-Heller-Str. 3 Bldg 17, D24105 Kiel, Germany
}

(C) 2011 Paulsen and Janssen; licensee BioMed Central Ltd. This is an Open Access article distributed under the terms of the Creative Commons Attribution License (http://creativecommons.org/licenses/by/2.0), which permits unrestricted use, distribution, and reproduction in any medium, provided the original work is properly cited.

amino acids important for the recruitment of TRAF proteins. These receptors have been mainly implicated in non-apoptotic processes including cellular activation, differentiation and survival [1], but they might also be involved in other forms of cell death, e.g. programmed necrosis as in the case of TNFR-2 [2].

Although the DD-containing receptors have been mainly associated with the induction of apoptosis, these receptors can also exert non-apoptotic functions in a wide range of different cell populations. Thus, several "death receptors" have been implicated in the signal induction for activation, migration, proliferation or differentiation. As an example, agonistic anti-CD95 antibodies caused massive CD95-induced hepatitis in normal mice but increased liver regeneration in mice subjected to hepatectomy [3]. For TNFR-1, it was proposed that receptor internalization and the formation of TNF receptosomes transmit pro-apoptotic signals, whereas plasma membrane-associated receptors trigger nonapoptotic signaling to activate 'nuclear factor 'kappalight-chain-enhancer' of activated B-cells' (NF- $\kappa \mathrm{B})$ [4]. Thus, the very same DD receptors can exert pro- or anti-apoptotic effects in a context-specific fashion and 
maybe depending on receptor clustering and internalization or on signaling thresholds governed by other simultaneous cell-cell-interactions.

\section{CD95 - the prototype of a death receptor}

The $45 \mathrm{kDa}$ type-I transmembrane protein CD95 is a member of TNFR family and serves as the prototypic death receptor for the immune system. CD95-dependent apoptosis is triggered by CD95L (FasL, APO-1L, TNFSF6) binding and clustering of surface CD95. Oligomerization initiates the recruitment of the 'Fas (CD95) associated protein with death domain' (FADD) and procaspase- 8 to form the 'death-inducing signaling complex' (DISC) [5,6]. In this multimolecular complex, procaspase- 8 undergoes autocatalytic cleavage resulting in the generation of active caspase- 8 , which in turn regulates the extrinsic pathway leading to apoptotic cell death $[7,8]$.

\section{CD95: a death receptor for lymphocyte homeostasis}

The importance of the CD95/CD95L-system for lymphocyte homeostasis became apparent from the initial observation that naturally occurring mice which developed massive lymphadenopathy and suffered from lymphoproliferative syndromes carried the causative mutations in the genes encoding either for CD95 $(l p r=$ lymphoproliferation) or for CD95L ( $g l d=$ generalized lymphoproliferative disease). In both types of mice, the impaired CD95/CD95L-interaction resulted in an accumulation of unconventional $\mathrm{T}$ cells (Thy $-1^{+} \mathrm{CD} 4{ }^{-} \mathrm{CD} 8^{-}$ $\mathrm{TCR} \alpha / \beta^{+} \mathrm{B} 220^{+}$) as well as in increased numbers of conventional $B$ cells and $C D 4^{+}$and $C D 8^{+} T$ cells [9-11]. This clearly suggested that signaling through the death receptor CD95 governs homeostasis of the lymphoid system. Since the observed pathology was apparently caused by a defective killing/dying capacity affecting both immature and mature cell populations, the phenotype might however have better been summarized as lymphoaccumulation rather than lymphoproliferation. Although functional defect mutants of CD95 or CD95L are rare in humans, the consequences of an impaired removal of pre-activated potentially dangerous cells are also characteristic for patients suffering from certain types of autoimmune lymphoproliferative syndrome (ALPS) [12,13].

In essence, $l p r / g l d$ - or ALPS-pathologies were associated with an impaired 'activation-induced cell death' (AICD). Briefly, AICD describes an activation-driven death that is associated with an induced increase in CD95L expression (e.g. following multiple TCR stimulations) which in turn results in suicidal or fratricidal CD95-mediated apoptosis. There is no doubt that death receptors play a prominent role in the development of AICD sensitivity $[14,15]$. However, it was also reported that death receptor independent signals via the TCR contribute to apoptosis sensitivity. One mechanism involves the cleavage of the 'hematopoietic progenitor kinase-1' (HPK-1), which in turn binds to the 'inhibitor of $\kappa \mathrm{B}(\mathrm{I} \kappa \mathrm{B})$ kinase' (IKK) complex and thereby interferes with pro-survival signaling by NF- $\kappa \mathrm{B}[16]$. Notably, activated $\mathrm{T}$ cells which are not restimulated die by 'activated cell autonomous death' (ACAD), a process which is also termed passive cell death or death by neglect and can also be observed under conditions of cytokine withdrawal [17].

Both ACAD and AICD have been implicated in thymocyte selection and the termination of the immune responses providing an effective means for the removal of useless cells. If one of the control mechanisms is missing, due to functional impairment of the trigger system or the involved signaling molecules, immature or mature cells might escape immune selection, and potentially dangerous autoreactive cells accumulate in lymphoid organs and in the periphery. Therefore, mutations in several genes encoding for apoptosis regulators (e.g. ligands, receptors, adapter proteins or caspases) cause immune dysfunction and severe autoimmunity as observed in ALPS patients and respective animal models.

Death receptors such as CD95 trigger the extrinsic apoptosis pathway. They deliver pro-apoptotic signals at the plasma membrane by formation of a DISC and by subsequent direct activation of a proteolytic caspase signaling cascade in so-called 'type I' cells or via an additional (intrinsic) mitochondrial amplification loop in 'type II' cells. As mentioned, the earlier studies on AICD suggested a prominent role of CD95 in this context $[6,14]$. However, more recent studies propose that the pro-apoptotic $\mathrm{BH} 3$-only protein 'Bcl-2-interacting mediator of cell death' (Bim), a member of the Bcl-2 protein family and thus a mediator of the mitochondrial apoptosis route, is also involved in the deletion of peripheral T cells [18-21]. Therefore, it has to be concluded that CD95 and Bim play a synergistic or cooperative role in the contraction phase of $\mathrm{T}$ cell responses, and link the different branches of the intracellular apoptosis machinery [22].

\section{CD95 - a dual-function receptor}

Apart from its primary pro-apoptotic role, follow-up studies revealed that CD95 might rather act as a dualfunction signaling receptor with tissue-specific functions and give rise to pro- and anti-apoptotic signals depending on the cellular microenvironment [8]. Thus, CD95 was found to affect proliferation, differentiation and migration processes as well as cytokine production in different hematopoietic and non-hematopoietic cell types. Moreover, a very recent study discovered that 
membrane-bound CD95L is essential for triggering cytotoxic activity, whereas soluble CD95L (generated when mCD95L is proteolytically cleaved by matrix metalloproteinases [23]) primarily promotes non-apoptotic activities [24] and even neutrophil chemotaxis [25].

As an apostil, non-apoptotic regulatory functions of the CD95L have also been suggested. This phenomenon, referred to as reverse or retrograde signaling, has been documented for several TNF ligands and increases the levels of complexity and plasticity during pro-and-antiapoptotic cell-cell communication. Here, CD95 operates as the ligand for membrane-bound CD95L to induce signal alterations in the CD95L-expressing cell. However, the available data on the role of CD95L reverse signaling in $\mathrm{T}$ cells are still fragmentary. What is known is that reverse signaling in different $\mathrm{T}$ cell subsets requires a presumably simultaneous TCR/CD3-engagement. In terms of outcome and signaling pathways, the reported findings are, however, still somewhat confusing since they span from promotion of proliferation to cell cycle arrest [23,26-30].

As indicated, anti-apoptotic effects of CD95 seem to depend on several parameters including the cell type and cellular context, the mode of ligation, and the activation-associated signaling threshold. However, nonapoptotic or even costimulatory consequences of CD95 engagement were only sporadically reported for instance during liver regeneration, development and functional recovery of the central nervous system or neurite outgrowth, and the proliferation of growth factor deprived fibroblasts [31]. Only recently, it became evident that CD95 ligation might be highly relevant for the modulation of TCR/CD3 signaling in primary $\mathrm{T}$ cells.

\section{CD95 as a non-apoptotic costimulatory molecule for T cells}

The textbooks tell that three signals are required for full activation and differentiation of resting $\mathrm{T}$ cells. The first signal emerges from an engagement of the TCR/CD3 complex, the second costimulatory signal is provided through the ligation of "classical" costimulatory receptors including CD28 or CD278 (ICOS) and the third signal for differentiation is provided by locally available cytokines. However, in recent years, TRAF binding receptors were identified as a second class of costimulatory receptors [1].

Based on experiments in gld- and lpr-mice, Alderson and colleagues provided first evidence for a potential role of CD95 in the activation of human T cells in 1993 when they reported a stronger proliferation and cytokine production in the presence of a functional CD95L/CD95-system [32]. It was subsequently reported that $\mathrm{CD} 95$-mediated costimulation involved activation of caspases in the absence of apoptosis
$[33,34]$. However, since $\mathrm{T}$ cell activation through the TCR alone apparently also depended on caspase processing, it was concluded that caspase activation plays a more general role in proliferative processes and under such costimulatory conditions might not necessarily be associated with death receptor signaling [34-36]. Along this line, caspase-8 mutations in humans were found to be associated with severe $\mathrm{T}$ cell associated immune dysfunction [37]. Whereas cleavage of the classical caspase substrate 'Poly(ADP-Ribose) Polymerase' (PARP) in this scenario has been initially observed by Alam et al. [34], recent data from others and our own experiments rather point to a non-apoptotic caspase activation that spares cleavage of apoptosis-relevant substrates such as PARP [38]. More precisely, we demonstrated an incomplete cleavage of caspase- 3 resulting in an accumulation of the p20 fragment under costimulatory conditions. Concomitantly, p17 and p19 fragments, which are characteristic for caspase-3 activity in apoptotic cells, were not seen in TCR/CD3-stimulated cells in the presence of CD95 agonists. We conclude that caspase activation is required for proliferation, but that non- or pro-apoptotic caspase activation is qualitatively different $[35,38,39]$. In view of our recent observation that the 'X-linked-inhibitor-of-apoptosis-protein' (XIAP) can interact with caspase- 3 and thereby block full caspase activation [38], we suggest that in naïve $T$ cells, CD95 initiates an incomplete cleavage of caspase-3, thereby presumably hindering the cleavage of pro-apoptotic substrates. Thus, caspase- 3 activation in this scenario might affect different substrates, which in turn are crucial for supporting a proliferative response. However, different caspase substrate repertoires associated with proliferation and apoptosis, respectively, have to be proven and characterized. So far, only limited numbers of putative anti-apoptotic caspase substrates have been described that include RasGAP [40] or HPK-1 [41-43]. In this context, a very recent study describe a systematic computational screening method of caspase cleavage sites to provide more insight into the substrate specificity of caspases and facilitate the discovery of putative novel substrates [44].

One mechanism to balance caspase activity during survival and cell death has been discussed by Kurokawa and Kornbluth [45]. In their review, they summarize how phosphorylation can alter activities of both caspases and their potential targets (e.g. kinases and phosphatases), and how these classes of signaling molecules are linked to control apoptosis and survival. As an example, phosphorylation of nuclear caspase- 2 at Ser122 by a DNA-dependent protein kinase induces non-apoptotic activation of the caspase and results in cell cycle arrest at a G2/M DNA damage checkpoint to allow DNA 
repair [46]. Thus, several caspases appear to be versatile enzymes with multiple functions beyond cell death induction depending on posttranslational modifications. Interestingly, in the context of non-apoptotic caspase activation by CD95 costimulation, a contribution to altered phosphorylation of caspases und their substrates has not been investigated. Furthermore, it still has to be clarified for non-apoptotic signaling, whether CD95 directly recruits or activates caspases via its adapter molecule FADD or whether CD95 only supports the TCR-mediated activation of caspases via a signaling complex formed for example by 'B-cell CLL/lymphoma associated 10' (Bcl-10), 'CARD-containing MAGUK protein1' (CARMA1) and 'mucosa-associated lymphoid tissue-1' (MALT-1) [47].

An additional level of regulation of life and death decisions in $\mathrm{T}$ cells is represented by the molecule 'cellular FLICE (caspase 8)-like inhibitory protein' (cFLIP). cFLIP can inhibit death receptor signaling and caspase- 8 activation, possibly through competition with caspase- 8 for the recruitment to FADD. However, it has also been shown that cFLIP mediates activation of full-length caspase- 8 at the DISC, which in turn results in caspase-8induced cleavage of cFLIP. Apparently, this process requires the cleavage of cFLIP to a p43-fragment [48]. More recently, it was argued that p22-cFLIP (but not p43) can activate NF- $\kappa$ B by directly interacting with the IKK complex [49]. Cleaved cFLIP then allows a more efficient recruitment of TRAF1/2, the 'receptor-interacting protein' (RIP1) and the the 'rapidly growing fibrosarcoma or rat fibrosarcoma-1' (Raf-1) protein to the cFLIP-caspase- 8 heterodimer. This complex supports the subsequent activation of NF- $\kappa \mathrm{B}$ and 'mitogen activated protein kinase' (MAPK) [50], both acting as key mediators of inflammatory or proliferative responses and survival. Since also Bcl-10 and MALT-1 associate to this complex [51], cFLIP could be considered as the candidate for determining life and death by directly linking CD95-costimulatory signals to TCR signaling pathways.

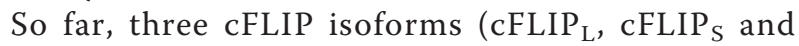
${ }^{c F L I P}{ }_{R}$ ) were identified, with $c F L I P_{S / R}$ presumably mediating a block in apoptosis by inhibiting caspase- 8 at the DISC as mentioned above. The role of $\mathrm{CFLIP}_{\mathrm{L}}$ regarding an inhibition at the DISC is still a matter of debate and seems to be regulated at the level of expression $[49,51,52]$. Likewise, the role of cFLIP in the activation of NF- $\kappa \mathrm{B}$ might be much more complex than described above. In fact, several groups reported inhibitory effects of cFLIP on CD95-induced NF- $\kappa$ B activation [53-55]. Further downstream of the CD95 apoptotic pathway, anti-apoptotic proteins including $\mathrm{Bcl}-2 / \mathrm{Bcl}-\mathrm{X}_{\mathrm{L}}$ and XIAP may prevent apoptosis $[7,38]$. An increased expression of anti-apoptotic checkpoint proteins in CD95-sensitive cells could therefore shift caspase-associated death signaling to NF- $\kappa \mathrm{B}$-associated proliferative signaling pathways in the course of cellular activation $[56,57]$.

\section{The two faces of non-apoptotic CD95 signaling in T cells}

As stated above, several earlier data pointed to a potential modulation of $\mathrm{T}$ cell activation by CD95 [32,33]. However, the molecular mechanism of the CD95 costimulatory function had never been elucidated in detail. Moreover, the published data about a "CD95 costimulation" have been somehow inconsistent, since CD95 has been described as a silencer or an enhancer of primary human $\mathrm{T}$ cell activation [32,33,36,50,58,59].

It was proposed that the expression of $\mathrm{CD} 95 \mathrm{~L}$ on 'antigen-presenting cells' (APC) would be responsible for antigen-specific deletion of primed peripheral $\mathrm{T}$ cells, eventually leading to $\mathrm{T}$ cell tolerance or immunosuppression [60-62]. Follow-up studies, however, provided evidence for alternate activities of APC-associated CD95L on naïve $\mathrm{T}$ cells, including the complete block of $\mathrm{T}$ cell activation and proliferation in the absence of apoptosis $[59,63]$. Of note, it is not yet clear whether the block in caspase- 8 activation observed under such conditions is due to an impaired recruitment to the DISC or whether caspase- 8 activation is directly abrogated in the CD95 complex. This suppression of T cell activation affected several proximal TCR signaling pathways including the recruitment and phosphorylation of ' $\zeta$-chain-associated protein of $70 \mathrm{kDa}$ ' ZAP70), 'phospholipase $C \gamma$ ' (PLC $\gamma)$, and 'protein kinase $C-\Theta$ ' $(\mathrm{PKC}-\Theta)$ into lipid rafts, thereby preventing the formation of a functional signaling platform. Furthermore, CD95-costimulated $\mathrm{T}$ cells displayed inefficient nuclear translocation of transcription factors including the 'nuclear factor of activated T cells' (NFAT), NF- $\kappa \mathrm{B}$ and the 'activator protein-1 (AP-1), reduced $\mathrm{Ca}^{2+}$-mobilization and decreased MAPK and caspase activation. As a consequence, Strauss and colleagues reported a down-regulation of activation markers and reduced secretion of several cytokines including IL-2, IFN $\gamma$ or TNF $\alpha$ (Figure 1). This block in cell activation through CD95 is in line with an earlier report by Chen and co-workers, who described an inhibition of $\mathrm{T}$ cell proliferation by "CD95L-painted" K562/B7-1 cells that was only partially caused by apoptosis induction [58]. However in both studies, a positive costimulatory effect of CD95L had not been noted.

It should be emphasized that this "negative costimulation" is in full agreement with our own observations employing high concentrations of immobilized CD95 agonists and thus reflects the inhibitory branch of CD95 signaling. However, our titration experiments revealed that low doses of the very same CD95 agonists drastically augment $\mathrm{T}$ cell activation and proliferation under 


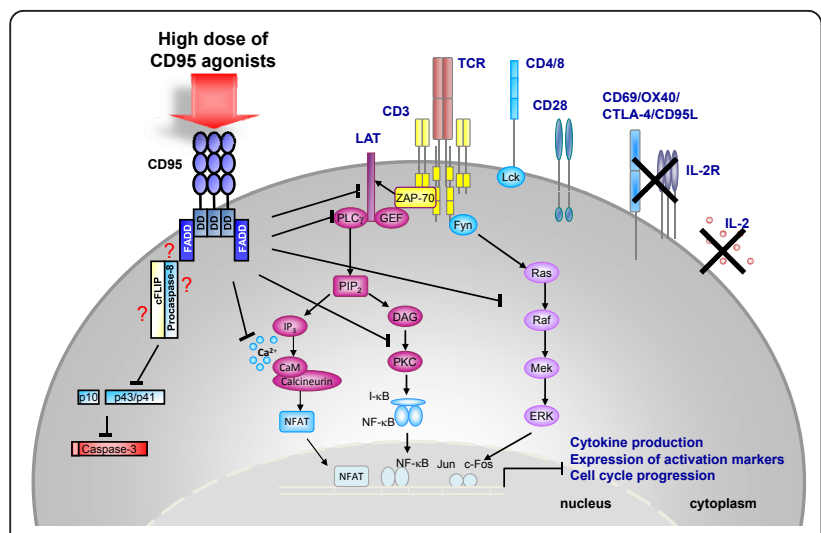

Figure 1 CD95L-expressing APC down-modulate T cell responses. High density CD95L, as expressed on transfectants or certain activated APC or mimicked by high amounts of CD95 agonists in vitro, engages membrane CD95 and interferes with proximal TCR signaling by inhibiting the phosphorylation of ZAP-70, PLC $\gamma$ and PKC, leading to inefficient nuclear translocation of transcription factors like NFAT, NF- $\kappa$ B and AP-1 (Jun/c-Fos). CD95 engagement under such conditions also prevents activation of caspases and MAPK as well as $\mathrm{Ca}^{2+}$-mobilization. Subsequently, TCRinduced cytokine production and upregulation of activation markers are impaired, resulting in a CD95L-mediated complete block of cell cycle progression in naïve $T$ cells.

otherwise unchanged conditions. This indicates that the outcome of CD95 ligation on naïve T cells largely depends on the "dose of agonist", resulting in opposite effects from a complete block of activation (at high doses) to prominent costimulatory activation (at lower concentrations) (Figure 2). Surprisingly, low doses of CD95 agonists promote cell cycle progression in a much higher portion of a given $\mathrm{T}$ cell population compared to conventional costimulation through the classical costimulatory molecule CD28. At the level of surface

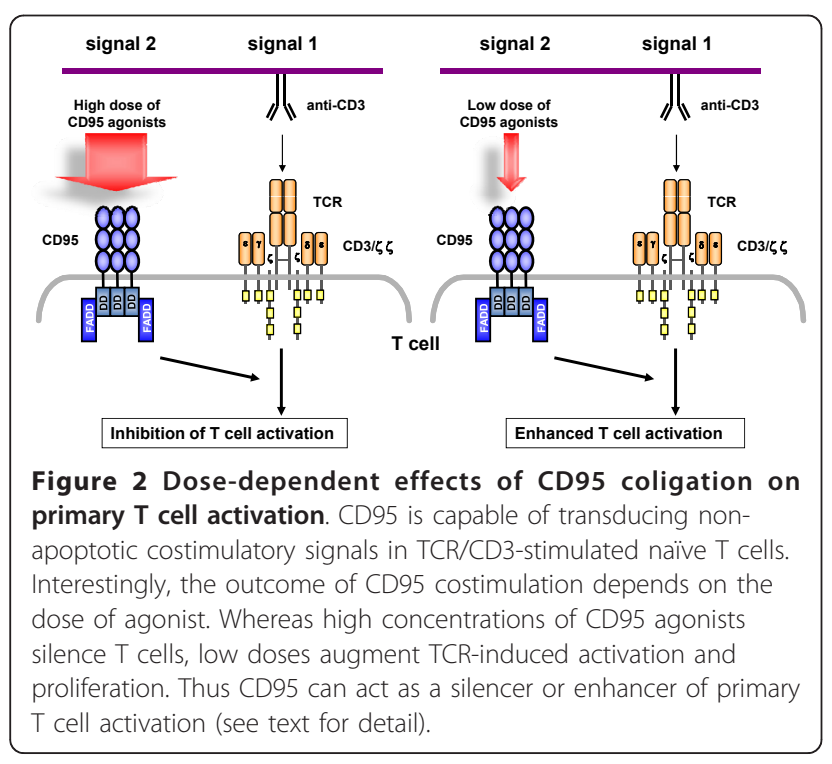

appearance of activation markers and regarding the activation of cell cycle regulatory proteins, CD95 triggering might in fact replace the conventional "signal 2" [39].

In our recent report, we provided a detailed analysis of the signaling events associated with the positive costimulatory activity of CD95 [39] that complemented the inhibitory features of the CD95/CD95L-system described by Strauss and colleagues [59]. Thus, CD95 ligation at low agonist concentrations promotes TCR-triggered MAPK phosphorylation, non-apoptotic caspase and NF$\kappa \mathrm{B}$ activation and the upregulation of activation markers and anti-apoptotic checkpoint proteins $[36,39,50]$. Furthermore, our analyses indicate an accelerated actindependent CD95 and TCR co-internalization as a mechanism to establish receptor interference and signaling crosstalk [39]. As a consequence, enhanced cell cycle progression and proliferation are associated with an increased cytokine production (IFN $\gamma, \mathrm{TNF} \alpha, \mathrm{IL}-2$ ) [32,33,36,39,50] (Figure 3).

Given that cFLIP and the Bcl-2 family member Bcl- $\mathrm{X}_{\mathrm{L}}$ (both upregulated in response to low concentrations of CD95 agonists [39]) are known for their capacity to interfere with apoptotic cell death $[7,64,65]$, we observed a more generalized partial apoptosis resistance upon primary TCR/CD3 activation, which was further enhanced upon costimulation via CD95 [39]. Interestingly in this context, it has recently been shown that the anti-apoptotic cFLIP isoforms do not just block the initiation of the extrinsic apoptotic pathway, but also result in

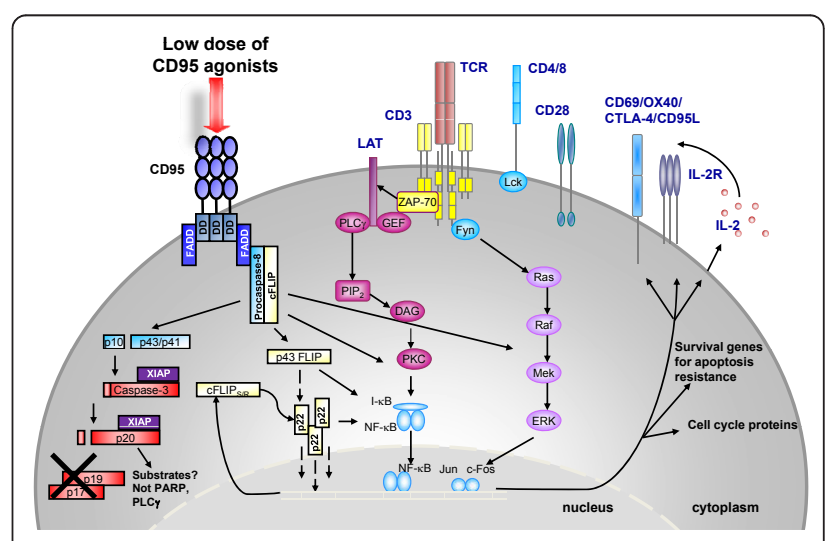

Figure 3 Costimulation with low doses of CD95 agonists increases primary $\mathrm{T}$ cell activation. CD95 coligation enhances MAPK and NF- $\kappa$ B activation in TCR-triggered cells and results in accelerated induction of activation markers, cell cycle regulatory proteins, cytokine secretion and cell cycle progression. The incomplete cleavage of caspase-3 into p20 fragments (possibly achieved by an interaction with XIAP) seems to be characteristic for non-apoptotic caspase activation and becomes more prominent upon CD95 costimulation. In line with the observed upregulation of anti-apoptotic proteins including $C F L I P_{R / S}$ and $B C l-X_{L}$ in the presence of low dose CD95 agonists, CD95/TCR-stimulated cells display a partial apoptosis resistance. 
increased survival after TCR engagement and protect from spontaneous apoptosis [66].

A dose-dependency of CD95 ligation had been observed earlier for CD95-sensitive SKW6.4 cells $[65,67]$. Lavrik and colleagues showed that a strong CD95 stimulation initiated death of this EBV-transformed lymphoblastoid B cell line, whereas CD95 stimulation below a certain threshold level triggered cFLIPdependent survival associated with MAPK and NF- $\kappa$ B activation. In fact, these experimental observations on life and death decisions and also on the role of cFLIP isoforms in this context fit nicely into the computational models that have been developed in a systems biology approach to better understand CD95 signaling consequences [65,67-69].

Based on our results in primary $\mathrm{T}$ cells, we proposed a comparable threshold mechanism in primary human $\mathrm{T}$ cells [39]. However, since freshly isolated $\mathrm{T}$ cells display apoptosis resistance even to high concentrations of soluble or immobilized CD95 agonists (in contrast to SKW6.4 cells or activated T cells), CD95 signaling shifts towards inhibition of cell proliferation as initially emphasized by Strauss et al. [59] or Chen et al. [58]. As a consequence, high concentrations block TCR signal initiation (without inducing cell death), whereas low concentrations result in a sustained amplification of the TCR-induced activation processes mentioned above (Figure 4).

Notably, differential CD95 ligation might also determine cell fate and apoptosis sensitivity outside the

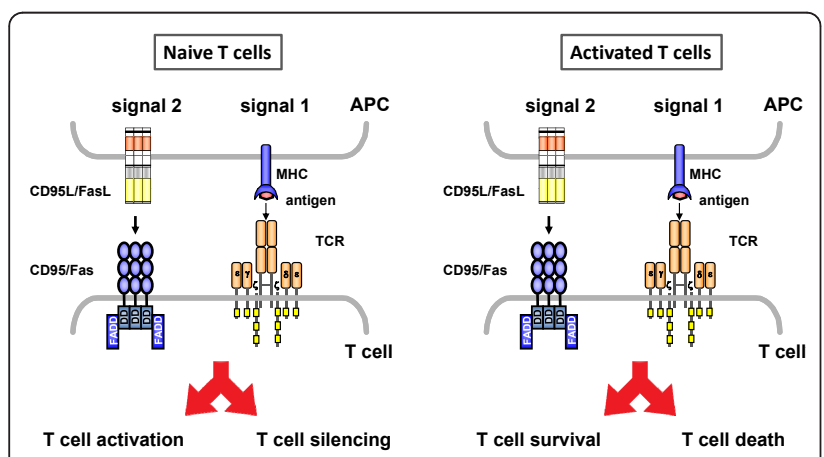

Figure 4 Modulation of T cell responses through CD95 in naïve versus activated $\mathbf{T}$ cells. The activation state of a given $\mathrm{T}$ cell (population) defines the signal threshold for pro- or non- apoptotic CD95 signaling. At the next level, the signal strength passing through CD95 determines whether signal transduction results in cell death, survival, cell cycle arrest or enhanced proliferation. In naïve CD95-resistant T cells, CD95 acts as a potent costimulatory receptor that can transduce activatory or inhibitory signals depending on the dose of CD95 agonists to modulate TCR/CD3 signal induction. Activated T cells are CD95-sensitive and undergo apoptosis when exposed to high concentrations of CD95L. In contrast, a weak CD95 stimulus (again below a certain threshold level) might induce survival signaling in the absence of detectable cell death. immune system. Schüngel and colleagues recently reported that depending on the efficacy of CD95 receptor activation or the strength of the CD95L signal (e.g. using monoclonal anti-CD95 antibodies or hexameric CD95L, respectively), hepatocytes and non-parenchymal liver cells can either behave as type I cells (following strong CD95 receptor activation) or as type II cells where the BH3-only protein Bid amplifies the weak death receptor signal to render the liver cells more sensitive to CD95-induced apoptosis [70].

\section{What could be the physiological relevance of dose- dependent $\mathrm{CD} 95$ signaling in $\mathrm{T}$ cells?}

The dose-dependency of CD95 signals calls for a closer look at the regulation of CD95L expression in cells that come into contact with resting and/or activated CD95 expressing T cells. Still, the role of CD95L expressed on epithelial cells of the thymus is controversially discussed. Some studies suggested a role of CD95L and/or CD95 during positive or negative selection [71-73]. However, most studies are again based on the gld-and lpr-models and describe phenomenology without providing detailed information about signaling alterations and consequences.

Although CD95L has been initially described as an inducible, more or less $\mathrm{T}$ cell specific, molecule, several studies document that also outside the thymus, CD95L is expressed on B cells [74], on APC including macrophages, 'dendritic cells' (DC) and Langerhans cells [75-77] and on tumour cells of different origin. With regard to tumour cells, (high level) CD95L expression might not only protect the tumour by inducing apoptosis in activated ("CD95-sensitive") tumour infiltrating cells, a mechanism that was referred to as 'tumor counterattack' [78], but could also block the activation of potentially tumour-reactive primary $\mathrm{T}$ cells for instance during metastatic spreading.

Regarding B cells or APC, it has been suggested that on those cells, CD95L might be upregulated in the course of an immune response or during cell maturation by yet unknown mechanisms accompanying antigen processing and presentation $[75,79,80]$. Thus, APC initially express low levels of CD95L. At the onset of an adaptive immune response to foreign antigens, the antigen presentation to naive $\mathrm{T}$ cell may therefore be associated with a costimulatory CD95 signal and result in enhanced activation and proliferation, as seen in vitro with suboptimal TCR stimulation in the presence of low amounts of CD95 agonists [39]. In this situation, CD95 triggering would support $\mathrm{T}$ cell expansion and the generation of effector $\mathrm{T}$ lymphocytes, which at the same time produce more 'T helper1' (Th1-)-type cytokines for the activation of 'natural killer' (NK) cells, macrophages and 'cytotoxic T cells' (CTLs). As a result of pathogen elimination, the expansion phase is followed by a 
contraction phase in which $\mathrm{T}$ cell numbers decline and reach their normal basal level. The reduction in $\mathrm{T}$ cell numbers could be accomplished and stabilized by the induction of apoptosis (AICD) in activated T cells on one hand and by preventing further activation of naive $\mathrm{T}$ cells on the other hand. According to the report by Strauss and colleagues [59] and our own observations using high doses of the CD95 agonists, this blockade could be achieved by high levels of CD95L, potentially on any neighboring cell. The recent reports therefore suggest that under physiological conditions, both the expression levels of CD95L and the threshold levels for CD95 "signal conversion" might be more relevant for the regulation and fine-tuning of the immune response than hitherto anticipated.

Along this line, it has been demonstrated that macrophages upregulate CD95L during an ongoing HIV-infection $[81,82]$ and thereby contribute to the apoptotic depletion of uninfected $\mathrm{CD}^{+} \mathrm{T}$ cells $[83,84]$. However, according to the report by Strauss et al. [59], another mechanism of reducing $\mathrm{T}$ cell numbers during HIV infection might be the block of proliferation of resting cells. Of course, the outcome of CD95 ligation very much depends on the state of activation of the respective $\mathrm{T}$ cell population. Infection with Cryptococcus neoformans results in an upregulation of CD95L on 'glucuronoxylomannan'/'tolllike receptor-4' (GXM/TLR-4)-triggered macrophages, associated with increased apoptotic $\mathrm{T}$ cell death in activated cells. As expected, also under such conditions, cell death induction is drastically reduced employing naïve $\mathrm{T}$ cells [85]. Likewise, CD95L-expressing DC trigger apoptosis of pre-activated cells but induce resistance of naïve $\mathrm{CD}^{+}$and $\mathrm{CD}^{+}{ }^{+} \mathrm{T}$ cells [86]. Under pathophysiological conditions, increased levels of CD95L might prevent initial $\mathrm{T}$ cell expansion. Respective scenarios have not only been reported for HIV [59], but also for 'cytomegalovirus' (CMV) [87], measles virus [88] and 'herpes simplex virus' (HSV) [89]. Raftery and colleagues [87] observed that CMV-infected DC not only down-modulate MHC molecules but also upregulate CD95L, thereby inducing cell death of activated $\mathrm{T}$ cells and non-deletional suppression of the surviving $\mathrm{T}$ cells. Thus, also an upregulation of CD95L on infected cells may provide an effective immune escape mechanism for certain pathogens. Recently, Puliaeva and colleagues further suggested that the CD95/ CD95L-system also plays a role in $\mathrm{T}$ cell/T cell-interactions. They showed in an in vivo mouse model that CD95 expression on $\mathrm{CD}_{4}^{+} \mathrm{T}$ cells provides an important signal for $\mathrm{CD} 4^{+} \mathrm{T}$ cell expansion and is required for optimal function of $\mathrm{CD}^{+}$effector CTL [90].

\section{Conclusion}

CD95 belongs to the TNFR superfamily and is best known for its capacity to execute cell death in CD95- sensitive cells. In this context, CD95-induced apoptosis plays an essential role in the maintenance of immune homeostasis and tolerance and in immune response termination. Dysregulation of pro-apoptotic functions contributes to several diseases including cancer or autoimmune syndromes and immunodeficiencies. In addition, non-apoptotic functions of CD95 in different cell types regulate proliferation, differentiation or chemotaxis. Also in T lymphocytes, CD95 acts as a dualfunction receptor that conveys its differential signals depending on the cellular microenvironment and the state of activation. From the most recent data, we conclude that low levels of CD95L on APC positively costimulate naïve $\mathrm{T}$ cells and thus support the expansion phase. In contrast, when CD95L is upregulated during the immune response, this may eventually result in the induction of apoptosis in activated cells and the prevention of activation of resting cells. Under pathophysiological conditions, the threshold levels might be shifted to higher expression of CD95L as a mechanism of immune evasion of certain pathogens.

\section{Abbreviations \\ AICD: activation-induced cell death; APC: antigen-presenting cell; BCI-X $X_{\llcorner}$B- cell lymphoma-extra large; CD95L: CD95 ligand; CFLIP: cellular FLICE (caspase 8)-like inhibitory protein; $C F L I P_{S / R}$ : CFLIP short/Raji; $_{\text {C FLIP }}$ : CFLIP Iong; CTL: cytotoxic T cell; DC: dendritic cell; DISC: death-inducing signaling complex; IFNY: interferon $\gamma$; IKB: inhibitor of NF-KB; IL-2: interleukin-2; MAPK: mitogen activated protein kinase; NF-kB: nuclear factor 'kappa-light-chain-enhancer' of activated B-cells; PARP: poly (ADP-ribose) polymerase; PLCY: phospholipase CY; TCR: T cell receptor; TNF: tumor necrosis factor; TNFR: TNF receptor; TRAF: TNF receptor-associated factor.}

\section{Acknowledgements}

We apologize to investigators whose work was not explicitly cited because of space and topical constrains. The intention of this Debate/Hypothesis article was to discuss the recent data on CD95 costimulation of primary human T cells as presented and awarded at the Signal Transduction Meeting 2010 in Weimar.

This work forms part of the PhD thesis of M. Paulsen. The project was sponsored by grants from the German Research Council (SFB 415, SFB 877) and the Medical Faculty of the Christian-Albrechts-University of Kiel.

\section{Authors' contributions}

MP designed and wrote the initial version of the article based on data obtained during the experimental work for completion of her doctoral thesis. The work was initiated and supervised by OJ. MP and OJ drafted the manuscript. Both authors read and approved the manuscript.

\section{Competing interests}

The authors declare that they have no competing interests.

Received: 28 January 2011 Accepted: 8 April 2011

Published: 8 April 2011

\section{References}

1. Watts TH: TNF/TNFR family members in costimulation of T cell responses. Annu Rev Immunol 2005, 23:23-68.

2. Chan FK, Shisler J, Bixby JG, Felices M, Zheng L, Appel M, Orenstein J, Moss B, Lenardo MJ: A role for tumor necrosis factor receptor-2 and receptor-interacting protein in programmed necrosis and antiviral responses. J Biol Chem 2003, 278:51613-51621. 
3. Desbarats J, Newell MK: Fas engagement accelerates liver regeneration after partial hepatectomy. Nat Med 2000, 6:920-923.

4. Schütze S, Tchikov V, Schneider-Brachert W: Regulation of TNFR1 and CD95 signalling by receptor compartmentalization. Nat Rev Mol Cell Biol 2008, 9:655-662.

5. Kischkel FC, Hellbardt S, Behrmann I, Germer M, Pawlita M, Krammer PH, Peter ME: Cytotoxicity-dependent APO-1 (Fas/CD95)-associated proteins form a death-inducing signaling complex (DISC) with the receptor. EMBO J 1995, 14:5579-5588.

6. Krammer PH: CD95's deadly mission in the immune system. Nature 2000, 407:789-795.

7. Krammer PH, Arnold R, Lavrik IN: Life and death in peripheral T cells. Nat Rev Immunol 2007, 7:532-542.

8. Strasser A, Jost PJ, Nagata S: The many roles of FAS receptor signaling in the immune system. Immunity 2009, 30:180-192.

9. Takahashi T, Tanaka M, Brannan Cl, Jenkins NA, Copeland NG, Suda T, Nagata S: Generalized lymphoproliferative disease in mice, caused by a point mutation in the Fas ligand. Cell 1994, 76:969-976.

10. Watanabe-Fukunaga R, Brannan Cl, Copeland NG, Jenkins NA, Nagata S: Lymphoproliferation disorder in mice explained by defects in Fas antigen that mediates apoptosis. Nature 1992, 356:314-317.

11. Rieux-Laucat F, Le Deist F, Fischer A: Autoimmune lymphoproliferative syndromes: genetic defects of apoptosis pathways. Cell Death Differ 2003, 10:124-133.

12. Fisher GH, Rosenberg FJ, Straus SE, Dale JK, Middleton LA, Lin AY, Strober W, Lenardo MJ, Puck JM: Dominant interfering Fas gene mutations impair apoptosis in a human autoimmune lymphoproliferative syndrome. Cell 1995, 81:935-946.

13. Rieux-Laucat F, Le Deist F, Hivroz C, Roberts IA, Debatin KM, Fischer A, de Villartay JP: Mutations in Fas associated with human lymphoproliferative syndrome and autoimmunity. Science 1995, 268:1347-1349.

14. Zheng L, Fisher G, Miller RE, Peschon J, Lynch DH, Lenardo MJ: Induction of apoptosis in mature T cells by tumour necrosis factor. Nature 1995, 377:348-351.

15. Li-Weber M, Krammer PH: Function and regulation of the CD95 (APO-1/ Fas) ligand in the immune system. Semin Immunol 2003, 15:145-157.

16. Brenner D, Golks A, Kiefer F, Krammer PH, Arnold R: Activation or suppression of NFkappaB by HPK1 determines sensitivity to activationinduced cell death. EMBO J 2005, 24:4279-4290.

17. Brenner D, Krammer PH, Arnold R: Concepts of activated T cell death. Crit Rev Oncol Hematol 2008, 66:52-64.

18. Hughes PD, Belz GT, Fortner KA, Budd RC, Strasser A, Bouillet P: Apoptosis regulators Fas and Bim cooperate in shutdown of chronic immune responses and prevention of autoimmunity. Immunity 2008, 28:197-205.

19. Hutcheson J, Scatizzi JC, Siddiqui AM, Haines GK, Wu T, Li QZ, Davis LS, Mohan C, Perlman H: Combined deficiency of proapoptotic regulators Bim and Fas results in the early onset of systemic autoimmunity. Immunity 2008, 28:206-217.

20. Weant AE, Michalek RD, Khan IU, Holbrook BC, Willingham MC, Grayson JM: Apoptosis regulators Bim and Fas function concurrently to control autoimmunity and CD8+ T cell contraction. Immunity 2008, 28:218-230.

21. Hildeman DA, Zhu Y, Mitchell TC, Bouillet P, Strasser A, Kappler J, Marrack P: Activated $T$ cell death in vivo mediated by proapoptotic bcl-2 family member bim. Immunity 2002, 16:759-767.

22. Bouillet P, O'Reilly LA: CD95, BIM and T cell homeostasis. Nat Rev Immunol 2009, 9:514-519.

23. Voss M, Lettau M, Paulsen M, Janssen O: Posttranslational regulation of Fas ligand function. Cell Commun Signal 2008, 6:11.

24. O'Reilly LA, Tai L, Lee L, Kruse EA, Grabow S, Fairlie WD, Haynes NM, Tarlinton DM, Zhang JG, Belz GT, et al: Membrane-bound Fas ligand only is essential for Fas-induced apoptosis. Nature 2009, 461:659-663.

25. Ottonello L, Tortolina G, Amelotti M, Dallegri F: Soluble Fas ligand is chemotactic for human neutrophilic polymorphonuclear leukocytes. Immunol 1999, 162:3601-3606.

26. Sun M, Ames KT, Suzuki I, Fink PJ: The cytoplasmic domain of Fas ligand costimulates TCR signals. J Immunol 2006, 177:1481-1491.

27. Paulsen M, Mathew B, Qian J, Lettau M, Kabelitz D, Janssen O: FasL crosslinking inhibits activation of human peripheral T cells. Int Immunol 2009, 21:587-598.

28. Sun M, Fink PJ: A new class of reverse signaling costimulators belongs to the TNF family. J Immunol 2007, 179:4307-4312.
29. Suzuki I, Martin S, Boursalian TE, Beers C, Fink PJ: Fas ligand costimulates the in vivo proliferation of CD8+ T cells. J Immunol 2000, 165:5537-5543.

30. Desbarats J, Duke RC, Newell MK: Newly discovered role for Fas ligand in the cell-cycle arrest of CD4+ T cells. Nat Med 1998, 4:1377-1382.

31. Peter ME, Budd RC, Desbarats J, Hedrick SM, Hueber AO, Newell MK Owen LB, Pope RM, Tschopp J, Wajant H, et al: The CD95 receptor: apoptosis revisited. Cell 2007, 129:447-450.

32. Alderson MR, Armitage RJ, Maraskovsky E, Tough TW, Roux E, Schooley K, Ramsdell F, Lynch DH: Fas transduces activation signals in normal human T lymphocytes. J Exp Med 1993, 178:2231-2235.

33. Kennedy NJ, Kataoka T, Tschopp J, Budd RC: Caspase activation is required for T cell proliferation. J Exp Med 1999, 190:1891-1896.

34. Alam A, Cohen LY, Aouad S, Sekaly RP: Early activation of caspases during T lymphocyte stimulation results in selective substrate cleavage in nonapoptotic cells. J Exp Med 1999, 190:1879-1890.

35. Falk M, Ussat S, Reiling N, Wesch D, Kabelitz D, Adam-Klages S: Caspase inhibition blocks human $\mathrm{T}$ cell proliferation by suppressing appropriate regulation of IL-2, CD25, and cell cycle-associated proteins. J Immunol 2004, 173:5077-5085.

36. Maksimow M, Soderstrom TS, Jalkanen S, Eriksson JE, Hanninen A: Fas costimulation of naive CD4 T cells is controlled by NF-kappaB signaling and caspase activity. I Leukoc Biol 2006, 79:369-377.

37. Chun HJ, Zheng L, Ahmad M, Wang J, Speirs CK, Siegel RM, Dale JK, Puck J, Davis J, Hall CG, et al: Pleiotropic defects in lymphocyte activation caused by caspase-8 mutations lead to human immunodeficiency. Nature 2002, 419:395-399.

38. Paulsen M, Ussat S, Jakob M, Scherer G, Lepenies I, Schütze S, Kabelitz D, Adam-Klages S: Interaction with XIAP prevents full caspase-3/-7 activation in proliferating human T lymphocytes. Eur J Immuno/ 2008, 38:1979-1987.

39. Paulsen M, Valentin S, Mathew B, Adam-Klages S, Bertsch U, Lavrik I, Krammer PH, Kabelitz D, Janssen O: Modulation of CD4(+) T-cell activation by CD95 co-stimulation. Cell Death Differ 2010.

40. Yang JY, Widmann C: Antiapoptotic signaling generated by caspaseinduced cleavage of RasGAP. Mol Cell Biol 2001, 21:5346-5358.

41. Arnold R, Liou J, Drexler HC, Weiss A, Kiefer F: Caspase-mediated cleavage of hematopoietic progenitor kinase 1 (HPK1) converts an activator of NFkappaB into an inhibitor of NFkappaB. J Biol Chem 2001, 276:14675-14684.

42. Arnold R, Frey CR, Muller W, Brenner D, Krammer PH, Kiefer F: Sustained JNK signaling by proteolytically processed HPK1 mediates IL-3 independent survival during monocytic differentiation. Cell Death Differ 2007, 14:568-575.

43. Brenner D, Golks A, Becker M, Muller W, Frey CR, Novak R, Melamed D, Kiefer F, Krammer PH, Arnold R: Caspase-cleaved HPK1 induces CD95Lindependent activation-induced cell death in T and B lymphocytes. Blood 2007, 110:3968-3977.

44. Song J, Tan H, Shen H, Mahmood K, Boyd SE, Webb Gl, Akutsu T, Whisstock JC: Cascleave: towards more accurate prediction of caspase substrate cleavage sites. Bioinformatics 2010, 26:752-760.

45. Kurokawa M, Kornbluth S: Caspases and kinases in a death grip. Cell 2009, 138:838-854

46. Shi M, Vivian CJ, Lee KJ, Ge C, Morotomi-Yano K, Manzl C, Bock F, Sato S, Tomomori-Sato C, Zhu R, et al: DNA-PKcs-PIDDosome: a nuclear caspase2-activating complex with role in G2/M checkpoint maintenance. Cell 2009, 136:508-520.

47. Thome M, Tschopp J: TCR-induced NF-kappaB activation: a crucial role for Carma1, Bcl10 and MALT1. Trends Immunol 2003, 24:419-424.

48. Kataoka T, Tschopp J: N-terminal fragment of C-FLIP(L) processed by caspase 8 specifically interacts with TRAF2 and induces activation of the NF-kappaB signaling pathway. Mol Cell Biol 2004, 24:2627-2636.

49. Golks A, Brenner D, Krammer PH, Lavrik IN: The c-FLIP-NH2 terminus (p22-FLIP) induces NF-kappaB activation. J Exp Med 2006, 203:1295-1305.

50. Kataoka T, Budd RC, Holler N, Thome M, Martinon F, Irmler M, Burns K, Hahne M, Kennedy N, Kovacsovics M, Tschopp J: The caspase-8 inhibitor FLIP promotes activation of NF-kappaB and Erk signaling pathways. Curr Biol 2000, 10:640-648.

51. Budd RC, Yeh WC, Tschopp J: cFLIP regulation of lymphocyte activation and development. Nat Rev Immunol 2006, 6:196-204. 
52. Zhang N, Hopkins K, He YW: The long isoform of cellular FLIP is essential for T lymphocyte proliferation through an NF-kappaB-independent pathway. J Immunol 2008, 180:5506-5511.

53. Wachter T, Sprick M, Hausmann D, Kerstan A, McPherson K, Stassi G, Brocker EB, Walczak H, Leverkus M: cFLIPL inhibits tumor necrosis factorrelated apoptosis-inducing ligand-mediated NF-kappaB activation the death-inducing signaling complex in human keratinocytes. J Biol Chem 2004, 279:52824-52834.

54. Kreuz S, Siegmund D, Rumpf JJ, Samel D, Leverkus M, Janssen O, Hacker G, Dittrich-Breiholz O, Kracht M, Scheurich P, Wajant H: NFkappaB activation by Fas is mediated through FADD, caspase- 8 , and RIP and is inhibited by FLIP. J Cell Biol 2004, 166:369-380.

55. Imamura R, Konaka K, Matsumoto N, Hasegawa M, Fukui M, Mukaida N, Kinoshita T, Suda T: Fas ligand induces cell-autonomous NF-kappaB activation and interleukin-8 production by a mechanism distinct from that of tumor necrosis factor-alpha. J Biol Chem 2004, 279:46415-46423.

56. Mandal M, Maggirwar SB, Sharma N, Kaufmann SH, Sun SC, Kumar R: Bcl-2 prevents CD95 (Fas/APO-1)-induced degradation of lamin B and poly (ADP-ribose) polymerase and restores the NF-kappaB signaling pathway. J Biol Chem 1996, 271:30354-30359.

57. Wajant H, Pfizenmaier K, Scheurich P: Non-apoptotic Fas signaling. Cytokine Growth Factor Rev 2003, 14:53-66.

58. Chen A, Zheng G, Tykocinski ML: Quantitative interplay between activating and pro-apoptotic signals dictates T cell responses. Cell Immunol 2003, 221:128-137.

59. Strauss G, Lindquist JA, Arhel N, Felder E, Karl S, Haas TL, Fulda S, Walczak H, Kirchhoff F, Debatin KM: CD95 co-stimulation blocks activation of naive T cells by inhibiting T cell receptor signaling. J Exp Med 2009, 206:1379-1393.

60. Mountz JD, Edwards CK: Murine models of autoimmunity: T-cell and Bcell defects. Curr Opin Rheumatol 1992, 4:612-620.

61. Zhang HG, Liu D, Heike Y, Yang P, Wang Z, Wang X, Curiel DT, Zhou T, Mountz JD: Induction of specific T-cell tolerance by adenovirustransfected, Fas ligand-producing antigen presenting cells. Nat Biotechnol 1998, 16:1045-1049.

62. Cancedda C, LeMaoult J, Harris PE, Suciu-Foca N, Cortesini R: Specific T-cell deletion by transfected human monocytes expressing Fas ligand and antigen. Transplant Proc 2001, 33:165-166.

63. Strauss G, Osen W, Knape I, Jacobsen EM, Muller SM, Debatin KM: Membrane-bound CD95 ligand expressed on human antigen-presenting cells prevents alloantigen-specific $T$ cell response without impairment of viral and third-party T cell immunity. Cell Death Differ 2007, 14:480-488.

64. Thome M, Tschopp J: Regulation of lymphocyte proliferation and death by FLIP. Nat Rev Immunol 2001, 1:50-58.

65. Bentele M, Lavrik I, Ulrich M, Stosser S, Heermann DW, Kalthoff $H$, Krammer PH, Eils R: Mathematical modeling reveals threshold mechanism in CD95-induced apoptosis. J Cell Biol 2004, 166:839-851.

66. Zhang N, Hopkins K, He YW: c-FLIP protects mature T lymphocytes from TCR-mediated killing. J Immunol 2008, 181:5368-5373.

67. Lavrik IN, Golks A, Riess D, Bentele M, Eils R, Krammer PH: Analysis of CD95 threshold signaling: triggering of CD95 (FAS/APO-1) at low concentrations primarily results in survival signaling. J Biol Chem 2007, 282:13664-13671.

68. Neumann L, Pforr C, Beaudouin J, Pappa A, Fricker N, Krammer PH, Lavrik IN, Eils R: Dynamics within the CD95 death-inducing signaling complex decide life and death of cells. Mol Syst Biol 2010, 6:352.

69. Fricker N, Beaudouin J, Richter P, Eils R, Krammer PH, Lavrik IN: Modelbased dissection of CD95 signaling dynamics reveals both a pro- and antiapoptotic role of c-FLIPL. J Cell Biol 2010, 190:377-389.

70. Schüngel S, Buitrago-Molina LE, Nalapareddy P, Lebofsky M, Manns MP, Jaeschke $H$, Gross A, Vogel A: The strength of the Fas ligand signal determines whether hepatocytes act as type 1 or type 2 cells in murine livers. Hepatology 2009, 50:1558-1566.

71. Castro JE, Listman JA, Jacobson BA, Wang Y, Lopez PA, Ju S, Finn PW, Perkins DL: Fas modulation of apoptosis during negative selection of thymocytes. Immunity 1996, 5:617-627.

72. Kishimoto $H$, Sprent J: Negative selection in the thymus includes semimature T cells. J Exp Med 1997, 185:263-271.

73. Boursalian TE, Fink PJ: Mutation in fas ligand impairs maturation of thymocytes bearing moderate affinity T cell receptors. J Exp Med 2003, 198:349-360.
74. Hahne M, Renno T, Schroeter M, Irmler M, French L, Bornard T, MacDonald HR, Tschopp J: Activated B cells express functional Fas ligand. Eur J Immunol 1996, 26:721-724.

75. Suss G, Shortman K: A subclass of dendritic cells kills CD4 T cells via Fas/ Fas-ligand-induced apoptosis. J Exp Med 1996, 183:1789-1796.

76. Lu L, Qian S, Hershberger PA, Rudert WA, Lynch DH, Thomson AW: Fas ligand (CD95L) and B7 expression on dendritic cells provide counterregulatory signals for T cell survival and proliferation. J Immunol 1997, 158:5676-5684.

77. De Panfilis G, Venturini M, Lavazza A, Mommaas MA, Semenza D, Torresani C, Pasolini G: The tolerogenic molecule CD95-L is expressed on the plasma membrane of human activated, but not resting, Langerhans' cells. Exp Dermatol 2003, 12:692-699.

78. Igney $\mathrm{FH}$, Krammer PH: Immune escape of tumors: apoptosis resistance and tumor counterattack. J Leukoc Biol 2002, 71:907-920.

79. Dockrell DH, Badley AD, Algeciras-Schimnich A, Simpson M, Schut R, Lynch DH, Paya CV: Activation-induced CD4+ T cell death in HIV-positive individuals correlates with Fas susceptibility, CD4+ T cell count, and HIV plasma viral copy number. AIDS Res Hum Retroviruses 1999, 15:1509-1518.

80. Lu G, Janjic BM, Janjic J, Whiteside TL, Storkus WJ, Vujanovic NL: Innate direct anticancer effector function of human immature dendritic cells. II. Role of TNF, lymphotoxin-alpha(1)beta(2), Fas ligand, and TNF-related apoptosis-inducing ligand. J Immunol 2002, 168:1831-1839.

81. Badley AD, Parato K, Cameron DW, Kravcik S, Phenix BN, Ashby D, Kumar A, Lynch DH, Tschopp J, Angel JB: Dynamic correlation of apoptosis and immune activation during treatment of HIV infection. Cell Death Differ 1999, 6:420-432.

82. Xu XN, Laffert B, Screaton GR, Kraft M, Wolf D, Kolanus W, Mongkolsapay J, McMichael AJ, Baur AS: Induction of Fas ligand expression by HIV involves the interaction of Nef with the T cell receptor zeta chain. J Exp Med 1999, 189:1489-1496.

83. Mueller YM, De Rosa SC, Hutton JA, Witek J, Roederer M, Altman JD, Katsikis PD: Increased CD95/Fas-induced apoptosis of HIV-specific CD8(+) T cells. Immunity 2001, 15:871-882.

84. Geleziunas R, Xu W, Takeda K, Ichijo H, Greene WC: HIV-1 Nef inhibits ASK1-dependent death signalling providing a potential mechanism for protecting the infected host cell. Nature 2001, 410:834-838.

85. Monari C, Pericolini E, Bistoni G, Casadevall A, Kozel TR, Vecchiarelli A: Cryptococcus neoformans capsular glucuronoxylomannan induces expression of fas ligand in macrophages. J Immunol 2005, 174:3461-3468.

86. Hoves S, Krause SW, Herfarth H, Halbritter D, Zhang HG, Mountz JD, Scholmerich J, Fleck M: Elimination of activated but not resting primary human CD4+ and CD8+ T cells by Fas ligand (FasL/CD95L)-expressing Killer-dendritic cells. Immunobiology 2004, 208:463-475.

87. Raftery MJ, Schwab M, Eibert SM, Samstag Y, Walczak H, Schonrich G: Targeting the function of mature dendritic cells by human cytomegalovirus: a multilayered viral defense strategy. Immunity 2001 15:997-1009.

88. Vuorinen T, Peri P, Vainionpaa R: Measles virus induces apoptosis in uninfected bystander $T$ cells and leads to granzyme $B$ and caspase activation in peripheral blood mononuclear cell cultures. Eur J Clin Invest 2003, 33:434-442.

89. Hoves S, Niller HH, Krause SW, Straub R, Gluck T, Mountz JD, Scholmerich J, Fleck M: Decreased T cell stimulatory capacity of monocyte-derived human macrophages following herpes simplex virus type 1 infection. Scand J Immunol 2001, 54:93-99.

90. Puliaeva I, Puliaev R, Shustov A, Haas M, Via CS: Fas expression on antigenspecific $T$ cells has costimulatory, helper, and down-regulatory functions in vivo for cytotoxic $T$ cell responses but not for $\mathrm{T}$ cell-dependent $\mathrm{B}$ cell responses. J Immunol 2008, 181:5912-5929.

doi:10.1186/1478-811X-9-7

Cite this article as: Paulsen and Janssen: Pro- and anti-apoptotic CD95 signaling in T cells. Cell Communication and Signaling 2011 9:7. 